\title{
SINTESIS DAN KARAKTERISASI ABU SEKAM PADI-LITIUM OKSIDA SERTA UJI AKTIVITAS KATALITIKNYA DALAM PEMBUATAN BIODIESEL DARI MINYAK BIJI MALAPARI
}

\author{
I N. Simpen ${ }^{1 *}$, N. L. Arpiwi ${ }^{2)}$, dan M. Indra Dwitama ${ }^{1)}$ \\ ${ }^{1)}$ Program Studi Kimia FMIPA Universitas Udayana, Bukit Jimbaran, Bali \\ ${ }^{2)}$ Program Studi Biologi FMIPA Universitas Udayana, Bukit Jimbaran, Bali \\ *E-mail: ngahsimpen@yahoo.com
}

\begin{abstract}
ABSTRAK
Penelitian ini dilakukan untuk menentukan sifat kimia fisik dari katalis abu sekam padi (ASP) termodifikasi litium oksida, optimasi suhu kalsinasi dalam sintesis katalis, serta menguji aktivitas katalitiknya dalam pembuatan biodiesel dari minyak biji malapari (Pongamia pinnata L.). Pembuatan katalis heterogen telah berhasil dilakukan melalui modifikasi ASP dengan litium karbonat. Modifikasi ASP dilakukan secara metode keramik melalui variasi suhu kalsinasi $700^{\circ} \mathrm{C}\left(\mathrm{Li}-\mathrm{ASP}_{700}\right), 800^{\circ} \mathrm{C}\left(\mathrm{Li}-\mathrm{ASP}_{800}\right)$, dan $900^{\circ} \mathrm{C}\left(\mathrm{Li}-\mathrm{ASP}_{900}\right)$. Katalis heterogen yang diperoleh, dikarakterisasi, dan diuji aktivitasnya untuk pembuatan biodiesel dari minyak biji malapari. Karakterisasi katalis heterogen meliputi keasaman dan kebasaan permukaan, Brunauer, Emmett dan Teller (BET) surface area, gugus fungsional, dan rasio Li/Si. Hasil penelitian menunjukkan bahwa keasaman permukaan katalis $\mathrm{Li}-\mathrm{ASP}_{700}, \mathrm{Li}_{-} \mathrm{ASP}_{800}$, dan Li-ASP 900 semuanya adalah $0 \mathrm{mmol} / \mathrm{g}$. Sementara, kebasaan permukaan tertinggi, surface area tertinggi, dan rasio $\mathrm{Li} / \mathrm{Si}$ tertinggi diperoleh pada katalis $\mathrm{Li}-\mathrm{ASP}_{700}$ berturut-turut yaitu 22,4883 mmol/g, 1,251 m²/g, dan 19,24 . Oleh karena itu, suhu kalsinasi optimum dalam pembuatan katalis tersebut adalah $700^{\circ} \mathrm{C}$. Katalis heterogen Li$\mathrm{ASP}_{700}$ mampu mengkonversi minyak biji malapari menjadi biodiesel optimum pada persentase katalis $3 \%$ (b/b) dengan yield $87,29 \%$.
\end{abstract}

Kata kunci: abu sekam padi termodifikasi litium oksida, katalis heterogen, minyak biji malapari, biodiesel

\begin{abstract}
This study was conducted to observe the physical chemical properties of lithium oxide modified rice husk ash (ASP) catalyst, to determine the optimum calcination temperature of the catalyst, as well as to test its activity in the production of biodiesel from pongamia oil (Pongamia pinnata L.). Preparation of heterogeneous catalysts have been carried out successfully through modification of ASP with lithium carbonate. Its modifications was done using ceramic method with variation of calcination temperatures such as $700^{\circ} \mathrm{C}\left(\mathrm{Li}-\mathrm{ASP}_{700}\right), 800^{\circ} \mathrm{C}\left(\mathrm{Li}-\mathrm{ASP}_{800}\right)$ and $900^{\circ} \mathrm{C}$ $\left(\mathrm{Li}-\mathrm{ASP}_{900}\right)$. The heterogeneous catalysts were characterized and tested its activity in the production of biodiesel from pongamia oil. The characterization of catalyst was done includes of the surface basicity and acidity, Brunauer, Emmett and Teller (BET) surface area, functional groups and Li/Si ratio. The results showed that the surface acidity of catalysts $\mathrm{Li}-\mathrm{ASP}_{700}, \mathrm{Li}-\mathrm{ASP}_{800}$, and $\mathrm{Li}-\mathrm{ASP}_{900}$ were zero mmol/g. Meanwhile, the highest surface basicity, BET surface area, and $\mathrm{Li} / \mathrm{Si}$ ratio of $\mathrm{Li}-\mathrm{ASP}_{700}$ catalyst were $22.4883 \mathrm{mmol} / \mathrm{g}, 1.251 \mathrm{~m}^{2} / \mathrm{g}$ and 19.24 respectively. Therefore, the optimum calcination temperature for preparation of catalyst was $700^{\circ} \mathrm{C}$. The heterogeneous catalyst had favorable activity in converting pongamia oil into biodiesel of catalyst percentage of $3 \%$ ( $/{ }_{w}$ ) and a maximum biodiesel yield of $87.29 \%$.
\end{abstract}

Keywords: heterogeneous catalyst, lithium oxide modified rice husk ash, pongamia oil, biodiesel

\section{PENDAHULUAN}

Katalis telah diterapkan secara luas dalam berbagai proses kimia baik dalam skala industri maupun laboratorium. Penerapan katalis meliputi berbagai bidang diantaranya produksi energi, produksi bahan kimia murni maupun curah serta industri makanan. Pada bidang produksi energi, katalis dimanfaatkan dalam produksi biodiesel. Dalam membuat biodiesel, digunakan katalis untuk mengoptimalkan produk reaksi, utamanya metil ester (Guo, et al., 2011). 
Biodiesel didefinisikan sebagai ester monoalkil dari minyak nabati atau lemak hewani (Srivastava, et al., 2000). Biodiesel disintesis melalui reaksi transesterifikasi senyawaan trigliserida dari minyak nabati atau lemak hewani dengan alkohol rantai pendek dibantu oleh katalis homogen basa kuat $(\mathrm{KOH}$ atau $\mathrm{NaOH})($ Knothe, et al., 2005). Penggunaan katalis homogen berdampak pada proses pemurnian dan pencucian produk akhir yang kurang ramah lingkungan dan kurang ekonomis (Xie et al., 2006). Disamping itu, penggunaan katalis tersebut memiliki kecenderungan meningkatkan korosifitas bila digunakan pada mesin (Lee et al., 2014). Di sisi lain, katalis heterogen memiliki keunggulan dibandingkan katalis homogen, diantaranya produksi biodiesel hanya menggunakan sedikit unit operasi serta proses pemisahan dan pemurnian produk yang lebih mudah (Atadashi et al., 2013). Katalis juga bersifat non-korosif, non-toksik, dan dapat diregenerasi setelah digunakan (regenerability) (Guo et al., 2011).

Abu sekam padi merupakan salah satu material padat yang seringkali dipandang sebagai limbah dan kurang bernilai. Abu sekam padi memiliki komposisi utama berupa silika atau $\mathrm{SiO}_{2}$ dengan kandungan 87-99\% dan juga sebagian kecil oksida anorganik seperti $\mathrm{CaO}, \mathrm{K}_{2} \mathrm{O}$ serta $\mathrm{MgO}$ (Della et al., 2002). Abu sekam padi diketahui memiliki luas permukaan yang besar sekitar $13,243 \mathrm{~m}^{2} / \mathrm{g}$ dan merupakan material yang memiliki banyak pori (Hindryawati et al., 2014). Karakteristik ini menjadikan abu sekam padi sebagai adsorben yang dapat diregenerasi (Nurhasni et al., 2014). Disamping itu juga, menjadikan abu sekam padi sebagai pengemban katalis yang potensial (Hindryawati et al., 2014). Pemanfaatan abu sekam padi sebagai material pengemban katalis alternatif dapat ditinjau sebagai langkah alternatif dalam memanfaatkan material yang kurang bernilai. Akbar et al. (2009) melaporkan bahwa senyawa yang mengandung silika sangat rendah menunjukkan aktivitas katalitik dalam transesterifikasi trigliserida, akan tetapi setelah dilakukan modifikasi dengan mengembankan kation alkali diketahui dapat menyediakan situs aktif yang mampu mengkatalisis reaksi tersebut.

Chen et al. (2013) telah memanfaatkan abu sekam padi sebagai prekursor litium yang sangat aktif dalam transesterifikasi minyak kedelai dengan metanol, dimana litium juga diketahui bersifat lebih tahan air dan udara luar dibandingkan natrium. Sementara itu, Hindryawati et al. (2014) menyebutkan bahwa abu sekam padi mampu bertindak sebagai material pengemban katalis yang baik bagi logam-logam alkali termasuk natrium, kalium, dan litium dalam pembuatan biodiesel dari minyak jelantah. Kedua penelitian tersebut telah membuktikan bahwa litium lebih unggul sebagai situs aktif katalis dalam abu sekam padi dibandingkan kation alkali lainnya. Akan tetapi, optimasi suhu kalsinasi dalam sintesis katalis heterogen dan karakterisasi sifat kimia fisik menarik diketahui. Pada penelitian ini, abu sekam padi dijadikan pengemban litium, yang dilakukan menggunakan metode keramik pada variasi suhu kalsinasi $700-900^{\circ} \mathrm{C}$. Selanjutnya, katalis heterogen dikarakterisasi sifat kimia fisiknya, meliputi keasaman dan kebasaan permukaan, gugus fungsional, luas permukaan spesifik dan rasio Li/Si. Hasil karakteristik terbaik diuji aktivitasnya dalam pembuatan biodiesel dari minyak biji malapari (Pongamia pinnata L.) yang merupakan minyak non-pangan potensial sebagai bahan baku biodiesel (Karmee et al., 2005; Bobade et al., 2012).

\section{MATERI DAN METODE}

\section{Bahan}

Bahan-bahan yang digunakan adalah biji malapari dari Pantai Lovina Singaraja, sekam padi dari Desa Batubulan Gianyar, $\mathrm{Li}_{2} \mathrm{CO}_{3}$ (Sigma Aldrich), etanol 95\%, spiritus, metanol proanalysis, aquades, $\mathrm{NaOH}, \mathrm{KOH}$, larutan $\mathrm{HCl}$, larutan asam oksalat, dan indikator Phenolphtalein (PP).

\section{Peralatan}

Alat yang digunakan meliputi labu leher dua, statif dan klem, karet sumbat, magnetic stirrer dan hotplate, stirrer bar, furnace, termometer, seperangkat alat refluks, seperangkat alat destilasi, neraca analitik, ayakan ukuran lubang 106-250 $\mu \mathrm{m}$, buret, gelas beaker, oven, blender, corong pisah, cawan porselen, desikator, dan pipet tetes, serta peralatan instrumentasi yaitu FTIR (fourier transform infra red), SAA (surface area analyzer 
$\mathrm{N}_{2}$ sorption), dan LIBS (laser induced breakdown spectroscopy).

\section{Cara Kerja \\ Preparasi Abu Sekam Padi}

Sekam padi dicuci terlebih dahulu dengan akuades untuk membersihkan sisa tanah dan pengotor lainnya, kemudian dijemur di bawah sinar matahari selama 48 jam hingga kering. Sekam padi yang telah kering, dibakar dalam nyala api sampai menghasilkan arang sekam padi yang berwarna hitam. Arang sekam padi direndam dalam larutan $\mathrm{HCl} 0,1 \mathrm{M}$ selama 1 jam guna demineralisasi logam renik ( $\mathrm{Al}, \mathrm{Ca}, \mathrm{K}, \mathrm{Mg}, \mathrm{Mn}$, dan Na) (Hindriyawati et al., 2014). Setelah direndam, arang sekam padi dicuci berulang-ulang dengan aquades (sampai netral), lalu dikeringkan dalam oven pada suhu $105-110^{\circ} \mathrm{C}$ selama 2 jam. Selanjutnya, arang sekam padi dipanaskan dalam tanur suhu $700^{\circ} \mathrm{C}$ selama 4 jam untuk menjadikan abu. Abu sekam padi yang dihasilkan, kemudian diayak dengan ayakan ukuran lubang antara 106$250 \mu \mathrm{m}$. Selanjutnya, abu tersebut ditempatkan dalam desikator dan diberi kode $\mathrm{ASP}_{\mathrm{o}}$ untuk eksperimen lebih lanjut.

\section{Modifikasi Abu Sekam Padi dengan Litium} Modifikasi dilakukan menggunakan metode keramik. Setiap 1,0 g ASP dicampurkan dengan 1,23 $\mathrm{g} \mathrm{Li}_{2} \mathrm{CO}_{3}$ pada cawan porselin kemudian didehidrasi pada suhu $200^{\circ} \mathrm{C}$ selama 30 menit sesuai Chen et al. (2013). Selanjutnya, dikalsinasi selama 4 jam pada variasi suhu $700^{\circ} \mathrm{C}$ $\left(\mathrm{Li}-\mathrm{ASP}_{700}\right), 800^{\circ} \mathrm{C}\left(\mathrm{Li}-\mathrm{ASP}_{800}\right)$, dan $900^{\circ} \mathrm{C}(\mathrm{Li}-$ $\mathrm{ASP}_{900}$ ). Katalis abu sekam padi tanpa dan termodifikasi litium kemudian dikarakterisasi sifat kimia fisiknya, meliputi keasaman dan kebasaan permukaan secara titrasi asam basa, penentuan gugus fungsional menggunakan FTIR, luas permukaan spesifik secara BET surface area serta rasio Li/Si dengan LIBS. Suhu kalsinasi optimum ditentukan dari katalis yang memiliki karakteristik kebasaan permukaan dan luas permukaan spesifik tertinggi.

\section{Uji Aktivitas Katalis}

Katalis heterogen dengan karakteristik optimum diuji aktivitasnya untuk pembuatan biodiesel dari minyak biji malapari dan sebagai pembanding digunakan $\mathrm{ASP}_{\mathrm{o}}$. Uji aktivitas diawali dengan ekstraksi minyak biji malapari secara soxhletasi dengan pelarut n-heksana (Arpiwi et al., 2017). Selanjutnya, dilakukan penyaringan minyak tersebut untuk membersihkan pengotor serta pemanasan pada suhu $110^{\circ} \mathrm{C}$ selama 30 menit, untuk menghilangkan kandungan air yang masih tersisa. Minyak kemudian dibiarkan mendingin hingga suhu berkisar $50-55^{\circ} \mathrm{C}$ (Bobade et al., 2012). Kemudian, dilanjutkan tahap reaksi transesterifikasi minyak untuk pembuatan biodiesel. Katalis dengan variasi persentase massa terhadap minyak $(1,3$, dan $5 \%, \mathrm{~b} / \mathrm{b})$ dicampurkan ke dalam metanol dengan rasio molar minyak:metanol 1:9 sambil diaduk selama 20 menit. Campuran katalis-metanol dipersiapkan terlebih dahulu untuk mengoptimalkan aktivitas katalis dan mencegah penyerapan air. Secara perlahan, campuran ditambahkan ke dalam minyak biji malapari. Reaksi dilakukan pada rentang suhu $60-65^{\circ} \mathrm{C}$ selama 180 menit dengan pengadukan konstan. Setelah reaksi selesai, pemanasan dihentikan dan hasil reaksi dibiarkan mendingin untuk kemudian ditimbang beratnya sebelum dipindahkan ke dalam corong pemisah (Hindryawati et al., 2014). Produk yang dihasilkan dibiarkan dalam corong pisah selama 12 jam sampai terbentuk 2 lapisan. Lapisan bagian atas merupakan biodiesel dan lapisan bagian bawah adalah gliserol dan katalis. Lapisan biodiesel dipisahkan dari lapisan gliserol dan katalis, kemudian disaring hingga diperoleh hasil yang jernih. Selanjutnya, didestilasi pada suhu $65-70^{\circ} \mathrm{C}$ untuk menghilangkan sisa metanol. Biodiesel yang dihasilkan kemudian ditimbang dan dihitung yieldnya menggunakan persamaan :

Yield Biodiesel $=\frac{\text { Massa biodiesel }}{\text { Massa hasil transesterifikasi }} \times 100 \%$

\section{HASIL DAN PEMBAHASAN}

\section{Karakterisasi Katalis}

\section{Keasaman dan Kebasaan Permukaan}

Hasil karakterisasi kebasaan permukaan katalis (Tabel 1) menunjukkan bahwa abu sekam padi sebelum modifikasi bersifat basa dan sedikit asam (Tabel 2). 
Tabel 1. Nilai kebasaan permukaan dan jumlah situs aktif basa katalis

\begin{tabular}{ccc}
\hline Jenis Katalis & $\begin{array}{c}\text { Kebasaan } \\
\text { Permukaan } \\
(\mathbf{m m o l} / \mathbf{g})\end{array}$ & $\begin{array}{c}\text { Jumlah Situs } \\
\text { Basa }(\mathbf{x ~ 1 0} \\
\text { situs/g) }\end{array}$ \\
\hline Li-ASP $_{700}$ & 22,4883 & 1,3542 \\
Li-ASP $_{800}$ & 22,3329 & 1,3449 \\
Li-ASP $_{900}$ & 21,8242 & 1,3143 \\
ASP $_{0}$ & 2,1663 & 1,3045 \\
\hline
\end{tabular}

Tabel 2. Nilai keasaman permukaan dan jumlah situs aktif asam katalis

\begin{tabular}{ccc}
\hline $\begin{array}{c}\text { Jenis } \\
\text { Katalis }\end{array}$ & $\begin{array}{c}\text { Keasaman } \\
\text { Permukaan } \\
(\mathbf{m m o l} / \mathbf{g})\end{array}$ & $\begin{array}{c}\text { Jumlah Situs } \\
\text { Asam }(\mathbf{x ~ 1 0} \\
\text { situs/g) }\end{array}$ \\
\hline Li-ASP $_{700}$ & 0 & 0 \\
Li-ASP $_{800}$ & 0 & 0 \\
Li-ASP $_{900}$ & 0 & 0 \\
ASP $_{o}$ & 0,0508 & 3,0617 \\
\hline
\end{tabular}

Sebelum modifikasi, kebasaan permukaan abu sekam padi $2,1663 \mathrm{mmol} / \mathrm{g}$ dan jumlah situs aktif basanya adalah $1,3045 \times 10^{21}$ situs $/ g$, sementara keasaman permukaannya 0,0508 $\mathrm{mmol} / \mathrm{g}$ dan jumlah situs asamnya adalah 3,0617 x $10^{19} \mathrm{situs} / \mathrm{g}$. Setelah abu sekam padi dimodifikasi dengan litium, memberikan peningkatan kebasaan permukaan secara siginifikan (Tabel 1). Abu sekam padi sebelum modifikasi memiliki kebasaan permukaan 2,1663 mmol/g (Dwitama dkk., 2016) dan setelah modifikasi pada suhu 700, 800 dan $900^{\circ} \mathrm{C}$ terjadi peningkatan berturut-turut menjadi 22,4883; 22,3329 dan 21,8242 situs/g. Modifikasi abu sekam padi dengan litium pada suhu 700, 800 dan $900^{\circ} \mathrm{C}$ yang semula terdapat situs basa 1,3045 x $10^{21}$ situs/g mengalami peningkatan jumlah situs aktif basa dengan nilai berturut-turut $1,3542 \mathrm{x}$ $10^{22} ; 1,3449 \times 10^{22}$ dan $1,3143 \times 10^{22}$ situs/g. Sementara, modifikasi abu sekam padi dengan litium diketahui tidak memberikan peningkatan sifat keasaman permukaan maupun situs aktif asam dari katalis (Tabel 2). Hal tersebut mengindikasikan bahwa modifikasi abu sekam padi dengan litium mampu meningkatkan situs basa. Hasil ini juga didukung oleh penelitian Chen et al. (2013), yang mengemukakan bahwa modifikasi abu sekam padi dengan litium dapat meningkatkan kekuatan basa.

\section{Gugus Fungsional}

Gugus fungsional dalam katalis yang terdeteksi oleh FTIR terangkum dalam Tabel 3, sementara spektra FTIR dari katalis ditunjukkan pada Gambar 1.
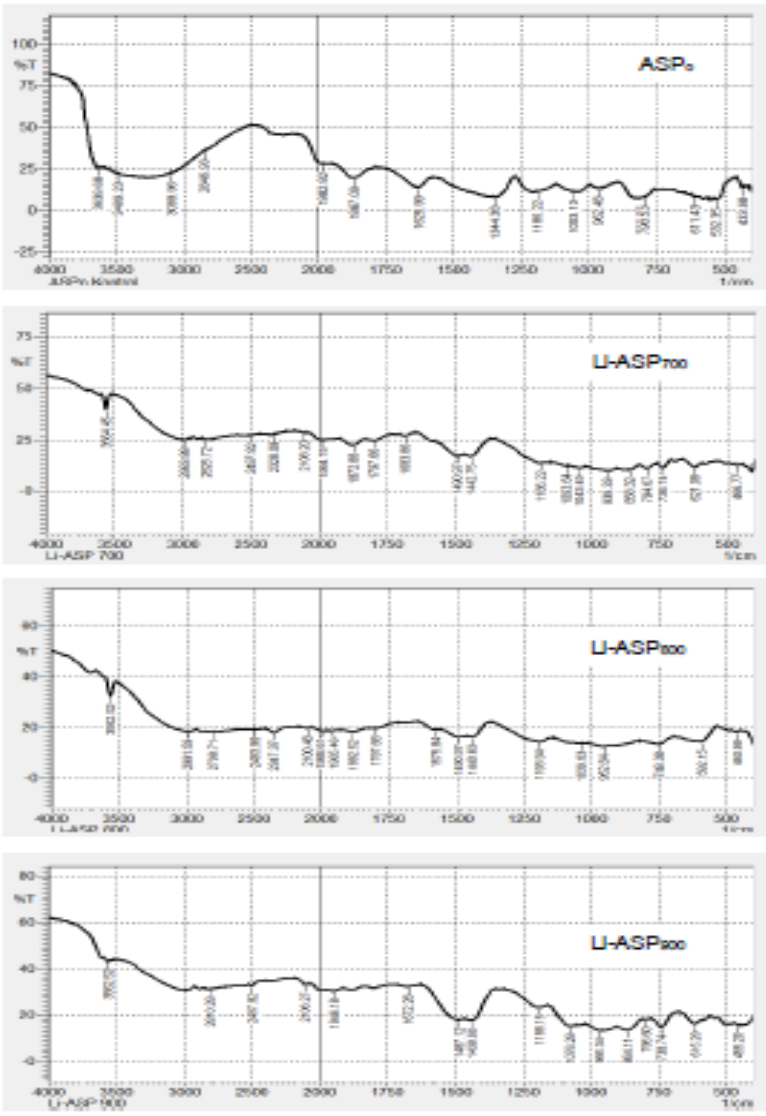

Gambar 1. Spektra FTIR katalis Li-ASP ${ }_{700}$, Li$\mathrm{ASP}_{800}, \mathrm{Li}-\mathrm{ASP}_{900}$ dan $\mathrm{ASP}_{\mathrm{o}}$ 
Tabel 3. Rangkuman gugus fungsional karakteristik katalis

\begin{tabular}{ccccc}
\hline Gugus Fungsional & \multicolumn{4}{c}{ Bilangan Gelombang $\left(\mathbf{c m}^{-\mathbf{1}}\right)$ untuk Jenis Katalis: } \\
\cline { 2 - 5 } Karakteristik & $\mathbf{A S P}_{\mathbf{0}}$ & Li-ASP $_{\mathbf{7 0 0}}$ & Li-ASP $_{\mathbf{8 0 0}}$ & Li-ASP $_{\mathbf{9 0 0}}$ \\
\hline Si-O-Si & 611,$43 ;$ & 621,$08 ; 1043,49$ & 592,$15 ; 1039,63$ & 615,$29 ; 1076,28$ \\
O-Si-O & 1053,13 & 794,67 & 794,67 & 796,6 \\
Li-O- & 798,53 & 466,67 & 460,99 & 455,2 \\
\hline
\end{tabular}

Puncak karakteristik pada rentang bilangan gelombang 600-620 $\mathrm{cm}^{-1}$ dan 1040-1070 $\mathrm{cm}^{-1}$, merupakan ikatan $\mathrm{Si}-\mathrm{O}-\mathrm{Si}$ sejalan dengan yang dikemukakan oleh Chen et al. (2013), sementara pada kisaran bilangan gelombang $794 \mathrm{~cm}^{-1}$ merupakan ikatan O-Si-O, dimana terdapat ikatan antara silika dalam abu sekam padi seperti halnya yang diungkapkan oleh Hindriyawati et al., (2014). Puncak-puncak ikatan Li-O- terdapat pada kisaran panjang gelombang $450-470 \mathrm{~cm}^{-1}$ seperti halnya yang dilaporkan oleh Ortiz et al. (2011). Puncakpuncak pada bilangan gelombang kisaran 1440$1493 \mathrm{~cm}^{-1}$ merupakan vibrasi dari $\mathrm{Li}_{2} \mathrm{CO}_{3}$ yang mana keberadaannya diduga karena masih terdapat $\mathrm{Li}_{2} \mathrm{CO}_{3}$ yang sepenuhnya belum bereaksi dan juga karena permukaan katalis yang menyerap $\mathrm{CO}_{2}$ dari udara selama preparasi (Chen et al., 2013). Hindriyawati et al. (2014) juga mengemukakan bahwa adanya puncak sekitar bilangan gelombang $3500 \mathrm{~cm}^{-1}$ menandakan keberadaan vibrasi tekuk dan ulur O-H yang diduga berasal dari molekul air yang terperangkap dalam katalis. Puncak yang ditemukan antara bilangan gelombang 2800 dan $3000 \mathrm{~cm}^{-1}$ mengindikasikan adanya persenyawaan organik yang masih terdapat pada katalis. Keberadaan gugus Li-O- pada katalis seperti yang telah dilaporkan oleh Ortiz et al. (2011), mengindikasikan bahwa modifikasi abu sekam padi dengan litium telah berhasil.

\section{Luas Permukaan Spesifik}

Luas permukaan spesifik berkaitan dengan kemampuan katalis dalam menyediakan tempat interaksi antara reaktan untuk membentuk produk yang diinginkan (activity dan selectivity). Karakteristik luas permukaan spesifik menjadi penting karena aktivitas katalis sangat berkaitan dengan fenomena adsorpsi dimana semakin besarnya luas permukaan spesifik, maka akan diikuti semakin banyaknya zat yang dapat teradsorpsi (Leonard dan Gates, 1995). Luas permukaan spesifik katalis (BET surface area), terangkum dalam Tabel 4.

Hasil karakterisasi luas permukaan spesifik (Tabel 4), menunjukkan bahwa luas permukaan spesifik abu sekam padi tanpa modifikasi $\left(\mathrm{ASP}_{\mathrm{o}}\right.$ ) adalah $158,329 \mathrm{~m}^{2} / \mathrm{g}$. Setelah dilakukan modifikasi dengan litium pada suhu 700, 800 , dan $900^{\circ} \mathrm{C}$ terjadi penurunan luas permukaan secara signifikan, tertinggi pada katalis Li-ASP 700 yaitu $1,251 \mathrm{~m}^{2} / \mathrm{g}$. Hal ini diduga terjadi akibat terembannya litium ke dalam $\mathrm{ASP}_{\mathrm{o}}$, dimana terjadi penetrasi molekul-molekul litium oksida ke dalam pori-pori tersebut. Fenomena ini sejalan dengan penelitian yang dilakukan oleh Hindryawati et al. (2014), bahwa terembannya logam-logam alkali seperti litium, natrium, dan kalium ke dalam pori abu sekam padi mengakibatkan penurunan luas permukaan spesifiknya.

Tabel 4. Luas permukaan spesifik katalis abu sekam padi tanpa dan termodifikasi litium oksid

\begin{tabular}{cc}
\hline Jenis Katalis & $\begin{array}{c}\text { Luas Permukaan } \\
\text { Spesifik }\left(\mathbf{m}^{2} / \mathbf{g}\right)\end{array}$ \\
\hline $\mathrm{Li}^{-A S P}$ & 1,251 \\
$\mathrm{Li}_{700}$ & 0,874 \\
$\mathrm{Li}_{800}-\mathrm{ASP}_{900}$ & 0,605 \\
$\mathrm{ASP}_{\mathrm{o}}$ & 158,329 \\
\hline
\end{tabular}

\section{Rasio $\mathrm{Li} / \mathrm{Si}$}

Tabel 5. Rasio Li/Si dalam jenis katalis

\begin{tabular}{cc}
\hline Jenis Katalis & Rasio Li/Si \\
\hline Li-ASP $_{700}$ & 19,24 \\
Li$-A_{S P}$ & 17,31 \\
Li-ASP $_{900}$ & 16,83 \\
ASP $_{0}$ & 0,02 \\
\hline
\end{tabular}

Abu sekam padi memiliki kandungan terbesar berupa silika (Della et al., 2002), sehingga pada karakterisasi dengan LIBS, unsur litium (Li) 
yang terdapat dalam katalis dibandingkan dengan unsur silikon ( $\mathrm{Si}$ ). Hasil analisis LIBS, unsur Si dideteksi pada panjang gelombang 251,61 $\mathrm{nm}$ dan unsur Li dideteksi pada panjang gelombang 670,79 nm. Tabel 5 menunjukkan bahwa metode keramik yang digunakan dalam modifikasi litium karbonat terhadap abu sekam padi telah berhasil mengembankan litium oksida ke dalam abu sekam padi. Hal ini ditunjukkan dengan meningkatnya rasio litium setelah modifikasi, dimana sebelum modifikasi rasio Li/Si 0,02 (Dwitama dkk., 2016) dan setelah modifikasi pada suhu 700, 800, dan $900^{\circ} \mathrm{C}$ mengalami peningkatan berturut-turut menjadi 19,24; 17,31; dan 16,83. Rasio $\mathrm{Li} / \mathrm{Si}$ tertinggi diperoleh pada suhu kalsinasi $700^{\circ} \mathrm{C}$.

\section{Uji Aktivitas Katalis dalam Pembuatan Biodiesel}

Uji aktivitas katalis dilakukan untuk mengetahui kemampuan katalis dalam menghasilkan produk yang diinginkan, yakni biodiesel (metil ester). Berdasarkan hasil karakterisasi katalis abu sekam padi termodifikasi litium oksida, diperoleh katalis dengan sifat kimia fisik terbaik yaitu katalis $\mathrm{Li}-\mathrm{ASP}_{700}$, sehingga uji aktivitas katalitiknya dilakukan terhadap katalis tersebut dan $\mathrm{ASP}_{\mathrm{o}}$ sebagai pembanding. Hasil uji aktivitas katalitik katalis tersebut dalam pembuatan biodiesel dari minyak biji malapari ditampilkan dalam Tabel 6.

Tabel 6. Hasil uji aktivitas katalis dalam pembuatan biodiesel dari minyak biji malapari

\begin{tabular}{cc}
\hline $\begin{array}{c}\text { Katalis dengan } \\
\text { Persentase Katalis } \\
\text { Terhadap Minyak }\end{array}$ & Yield Biodiesel (\%) \\
\hline Li-ASP $_{700}(1 \%)$ & 78,57 \\
Li-ASP $_{700}(3 \%)$ & 87,29 \\
Li-ASP $_{700}(5 \%)$ & 86,78 \\
$\mathrm{ASP}_{\mathrm{o}}(3 \%)$ & 22,57 \\
\hline
\end{tabular}

Berdasarkan Tabel 6, yield biodiesel tertinggi dihasilkan oleh katalis $\mathrm{Li}-\mathrm{ASP}_{700}$ pada persentase katalis terhadap minyak $3 \%$ (b/b) dengan yield $87,29 \%$, sementara yield biodiesel dari katalis tanpa modifikasi $\left(\mathrm{ASP}_{\mathrm{o}}\right)$ adalah $22,57 \%$. Yield biodiesel yang signifikan antara kedua katalis tersebut menunjukkan bahwa katalis abu sekam padi termodifikasi litium oksida suhu $700^{\circ} \mathrm{C}\left(\mathrm{Li}^{-} \mathrm{ASP}_{700}\right)$ memiliki aktivitas lebih tinggi dibandingkan katalis tanpa modifikasi. Ini berarti bahwa modifikasi tersebut telah dapat meningkatkan secara signifikan yield biodiesel dari minyak biji malapari.

\section{SIMPULAN DAN SARAN}

\section{Simpulan}

Suhu kalsinasi optimum dalam pembuatan katalis heterogen abu sekam padi termodifikasi litium adalah $700^{\circ} \mathrm{C}$ dengan kebasaan permukaan $22,4883 \mathrm{mmol} / \mathrm{g}$, luas permukaan spesifik (BET surface area) $1,251 \mathrm{~m}^{2} / \mathrm{g}$, dan rasio $\mathrm{Li} / \mathrm{Si} 19,24$. Katalis heterogen abu sekam padi termodifikasi litium oksida suhu kalsinasi $700^{\circ} \mathrm{C}$ memiliki aktivitas signifikan dalam mengkonversi minyak biji malapari menjadi biodiesel, dengan persentase katalis optimum $3 \%(\mathrm{~b} / \mathrm{b})$ menghasilkan biodiesel dengan yield tertinggi $87,29 \%$, dibandingkan abu sekam padi tanpa modifikasi $22,57 \%$.

\section{Saran}

Perlu dilakukan penelitian lebih lanjut dalam pembuatan biodiesel menggunakan reuse katalis abu sekam padi termodifikasi litium oksida.

\section{UCAPAN TERIMA KASIH}

Penulis sampaikan ucapan terima kasih kepada semua pihak yang telah memberikan kontribusi pemikiran dan dukungan fasilitas hingga penelitian dapat terselesaikan.

\section{DAFTARPUSTAKA}

Akbar, E., Binitha, N., Yaakob, Z., Kamarudin S.K., and Salimon, J., 2009, Preparation of $\mathrm{Na}$ doped $\mathrm{SiO}_{2}$ solid catalysts by the solgel method for the production of biodiesel from jatropha oil, Green Chem, 11: 18621866.

Arpiwi, N.L., Negara, IM.S., and Simpen, IN., 2017, Selection of high oil yielding trees of Millettia pinnata (L.) Panigrahi, vegetative propagation and growth in the field, J. Trop. Life. Science, 7(3): 258-262. 
Atadashi, I.M., Aroua, M.K., Abdul, A.A.R., and Sulaiman, N.M.N., 2013, The effects of catalysts in biodiesel production: A review, Journal of Industrial and Engineering Chemistry, 19(1): 14-26.

Bobade S.N. and Khyade, V.B, 2012, Detail study on the properties of Pongamia Pinnata (Karanja) for the production of biofuel, Research Journal of Chemical Sciences, 2(7): 16-20.

Chen, K.T., Wang, J.X., Dai, Y.M., Wang, P.H., Liou, C.Y., Nien, C.W., and Chen, C.C., 2013, Rice husk ash as a catalyst precursor for biodiesel production, Journal of the Taiwan Institute of Chemical Engineers, 44(4): 622-629.

Della, V.P., Kuhn I., and Hotza D., 2002, Rice husk ash as an alternate source for active silica production, Materials Letters, 57(4): 818-821.

Dwitama, M.I., Nazib, M., Sitepu, O.C., Suandi, D.A.P., dan Simpen, IN., 2016, Konversi minyak biji malapari (Pongamia pinnata L.) menjadi biodiesel melalui pemanfaatan katalis heterogen abu sekam padi termodifikasi Li, Jurnal Kimia, 10(2): 236244.

Guo, F., and Fang, Z, 2011, Biodiesel production with solid catalysts, Biodiesel Feedstocks and Processing Technologies, 1-21.

Hindryawati, N., Maniam, G.P., Karim, M.R., and Chong, K.F., 2014, Transesterification of used cooking oil over alkali metal ( $\mathrm{Li}, \mathrm{Na}$, $\mathrm{K})$ supported rice husk silica as potential solid base catalyst Engineering Science and Technology, an International Journal, 17(2): 95-103.
Karmee, S.K., and Chadha, A., 2005, Preparation of biodiesel from crude oil of Pongamia pinnata, Bioresource Technology, 96: $1425-1429$.

Knothe, G., van-Gerpen, J., and Krahl, J., 2005, The biodiesel handbook, $1^{\text {st }}$ edition, AOCS Press, Champaigne-Illinois

Lee, A.F., Bennett, J.A., Manayil, J.C., and Wilson, K., 2014, Heterogeneous catalysis for sustainable biodiesel production via esterification and transesterification, Chemical Society Reviews, 43: 7887-7916.

Leonard, V.I. and Gates, B.C., 1995, Materials chemistry: an emerging discipline, American Chemical Society, Wasington

Nurhasni, H., dan Nubzah, S., 2014, Sekam padi untuk menyerap ion logam tembaga dan timbal dalam air limbah, Valensi, 4(1): 3644.

Ortiz, J. L., Martinez, D.L.C., Gomez, Y., and Pfeiffer, H., 2011, Towards understanding the thermoanalysis of water sorption on lithium orthosilicate, Thermochimica Acta, 515: 73-78.

Srivastava, A. and Prasad, R., 2000, Triglycerides based Diesel Fuel, Renewable and Sustainable Energy Review, 4: 111 - 133.

Xie, W. and Li, H., 2006, Alumina-supported potassium iodide as a heterogeneous catalyst for biodiesel production from soybean oil, Journal of Molecular Catalysis A: Chemical, 255: 1-9.

Yang, R.T., 2003, Adsorbent: Fundamentals and Applications, $1^{\text {st }}$ edition, John Willey and Sons Inc, New Jersey. 